\title{
Genetically Encoded Voltage Indicators: Opportunities and Challenges
}

\author{
날 Helen H. Yang ${ }^{1}$ and ${ }^{\circledR}$ François St-Pierre ${ }^{2,3}$ \\ ${ }^{1}$ Department of Neurobiology, Stanford University, Stanford, California 94305, ${ }^{2}$ Department of Neuroscience, Baylor College of Medicine, Houston, Texas \\ 77030, and ${ }^{3}$ Department of Electrical and Computer Engineering, Rice University, Houston, Texas 77005
}

\begin{abstract}
A longstanding goal in neuroscience is to understand how spatiotemporal patterns of neuronal electrical activity underlie brain function, from sensory representations to decision making. An emerging technology for monitoring electrical dynamics, voltage imaging using genetically encoded voltage indicators (GEVIs), couples the power of genetics with the advantages of light. Here, we review the properties that determine indicator performance and applicability, discussing both recent progress and technical limitations. We then consider GEVI applications, highlighting studies that have already deployed GEVIs for biological discovery. We also examine which classes of biological questions GEVIs are primed to address and which ones are beyond their current capabilities. As GEVIs are further developed, we anticipate that they will become more broadly used by the neuroscience community to eavesdrop on brain activity with unprecedented spatiotemporal resolution.
\end{abstract}

Key words: biosensors; fluorescence imaging; genetically encoded voltage indicators (GEVI); voltage imaging

\section{Significance Statement}

Genetically encoded voltage indicators are engineered light-emitting protein sensors that typically report neuronal voltage dynamics as changes in brightness. In this review, we systematically discuss the current state of this emerging method, considering both its advantages and limitations for imaging neural activity. We also present recent applications of this technology and discuss what is feasible now and what we anticipate will become possible with future indicator development. This review will inform neuroscientists of recent progress in the field and help potential users critically evaluate the suitability of genetically encoded voltage indicator imaging to answer their specific biological questions.

\section{Introduction}

The electrical potential across the plasma membrane of neurons is a key information carrier in the brain (Ainsworth et al., 2012). Monitoring the voltage dynamics of individual neurons, from synaptic inputs to axonal outputs, is therefore critical for understanding the neural processes that underlie behavior. Although electrophysiological methods for monitoring voltage have been successfully used for several decades, optical monitoring of voltage can enable experiments that are difficult or impossible to perform with electrophysiology. Specifically, imaging can allow tracking of voltage signals with higher spatial resolution and from

Received April 25, 2016; revised July 14, 2016; accepted July 25, 2016.

F.S.-P. was supported by the McNair Medical Institute. H.H.Y. was supported by a Stanford Interdisciplinary Graduate Fellowship and National Institutes of Health Grants R01 EY022638 and R21 NS081507. We thank Mingshan Xue, Shane Heiney, and members of the F.S.-P. laboratory for helpful comments on this review.

F.S.-P. has filed a patent application for a genetically encoded voltage indicator design. H.H.Y. declares no competing financial interests.

Correspondence should be addressed to Dr. François St-Pierre, Department of Neuroscience, Baylor College of Medicine, Houston, TX 77030. E-mail: stpierre@bcm.edu.

DOI:10.1523/JNEUROSCI.1095-16.2016

Copyright $\odot 2016$ the authors $\quad 0270-6474 / 16 / 369977-13 \$ 15.00 / 0$ multiple subcellular locations, neighboring neurons, or brain areas. Optical methods can also more easily record voltage from small subcellular areas, such as dendritic spines.

The first optical reporters of voltage were small-molecule dyes, and these have been used to follow voltage dynamics across single neurons and over larger cortical areas (for review, see Chemla and Chavane, 2010; Tsytsarev et al., 2014; Antic et al., 2016). The need for optical voltage recording with selective labeling of specific cell types motivated the development of proteinbased sensors typically called genetically encoded voltage indicators (GEVIs). In contrast to voltage-sensitive dyes, GEVIs can leverage the extensive catalog of cell type-specific promoters in genetically tractable model organisms, such as worms, flies, and mice, thereby enabling genetic dissection of voltage dynamics. However, because of the excellent performance of genetically encoded calcium indicators (GECIs) compared with that of the first generations of GEVIs, most neuroscientists have relied on GECIs to follow neural activity via its associated calcium fluxes (for review, see Ibraheem and Campbell, 2010; Looger and Griesbeck, 2012; Broussard et al., 2014). Nevertheless, GEVIs and GECIs report distinct cellular events, motivating the develop- 
ment and deployment of both types of indicators. For instance, calcium dynamics cannot always track hyperpolarizations and subthreshold depolarizations, and the relatively slow kinetics of calcium transients (Helmchen et al., 1996, 1997; Koester and Sakmann, 2000) limit the ability of GECIs to report rapid trains of action potentials.

The interest in GEVIs has sparked development efforts from multiple laboratories around the world. The performance and mechanisms of the resulting indicators have been reviewed previously (e.g., Gong, 2015; Knöpfel et al., 2015; St-Pierre et al., 2015; Storace et al., 2016). Hybrid voltage indicators, which combine a voltage-sensitive dye with a genetically encoded component, have also been discussed previously (Peterka et al., 2011; Mutoh et al., 2012). Here, we instead focus on the overall opportunities and challenges of GEVI imaging. We first systematically evaluate GEVIs across all key factors that determine sensor performance. We next discuss the suitability of GEVIs for addressing biological questions and highlight studies where they have already been used for biological discovery. Throughout our review, we emphasize the present capabilities of GEVIs to help readers determine which types of questions GEVIs can help address now and which require indicators with greater performance than currently available sensors. By highlighting both the advantages and limitations of GEVIs for neuroscience, we hope that our article will inspire novel approaches for further sensor development and new studies that leverage their unique features.

\section{Developing GEVIs}

GEVIs have been reported since 1997 (Siegel and Isacoff, 1997), with early efforts reviewed previously (Baker et al., 2008; Mutoh et al., 2012). They are based on two general mechanisms. In one class, one or more fluorescent proteins are coupled to four-pass voltage sensing domains (VSDs) from voltage-sensitive phosphatases (Dimitrov et al., 2007), potassium channels (Siegel and Isacoff, 1997), sodium channels (Ataka and Pieribone, 2002), or proton channels (Kang and Baker, 2016). Voltage-induced conformational changes in the VSD can then perturb the chemical environment of the fluorescent protein chromophore, thereby modulating its brightness (Jin et al., 2012). Alternatively, these movements can alter the efficiency of Fluorescence Resonance Energy Transfer (FRET) between two attached fluorescent proteins (Lundby et al., 2010). In other words, the VSD acts as a mechanoelectrical transducer, converting electric field fluctuations to movement, whereas the coupled fluorescent proteins are optomechanical transducers, converting VSD movements into a change in photon emission.

Seven-pass engineered microbial rhodopsins have been used as the scaffold for a second class of GEVIs (Kralj et al., 2011; Maclaurin et al., 2013). These indicators act as coupled chemoelectrical and optochemical transducers: the strength of the transmembrane electrical field affects the probability that a cytoplasmic proton will protonate the rhodopsin chromophore, retinal; in turn, the protonation state of retinal regulates its fluorescence. In variants of this design, an attached fluorescent protein serves as a FRET donor to the rhodopsin (Gong et al., 2014; Zou et al., 2014). The electric field is thought to impact the absorption spectra of the rhodopsin, thereby affecting FRET efficiency and thus photon emission from the coupled fluorescent protein. GEVIs based on this mechanism have been dubbed electrochromic FRET or FRET-opsin sensors.

To be of broad applicability, a GEVI must meet several performance criteria. To report transmembrane voltage, it must be localized to the plasma membrane. Additionally, the sensor should not disrupt neuronal viability or excitability at typical expression levels. To detect small voltage signals, a sensor should be bright and exhibit a large response amplitude. It should be photostable, enabling imaging for a long duration with a minimal reduction in brightness over time. The kinetics of GEVI responses should also be sufficiently fast to detect rapid electrical events, such as action potentials. Critically, for many in vivo applications, an ideal sensor should be compatible with microscopy techniques for deep tissue imaging. An ideal voltage indicator should also enable mapping of its optical readout into absolute voltage values and be spectrally compatible with other optical actuators and indicators. Finally, broader GEVI utility is predicated on their ability to function across a number of key model systems in neuroscience. In the following sections, we discuss these challenges in detail and highlight the progress in indicator development over the last few years. Sensor performance metrics and challenges are summarized in Figure 1.

\section{Plasma membrane localization}

To report changes in voltage, GEVIs must reach and be properly inserted in the plasma membrane. Because indicator molecules trapped in the cytoplasm typically fluoresce but do not respond to voltage fluctuations (Kralj et al., 2012), suboptimal membrane localization of GEVIs reduces a neuron's apparent fluorescence response to voltage transients. Pixel selection algorithms can be used to minimize the impact of these nonresponsive cellular areas when imaging single cells at high magnification (Kralj et al., 2012). However, such strategies become less effective under lower magnification, for example, when imaging larger populations of cells, as each cell will only correspond to a small number of pixels.

GEVIs must use cells' endogenous protein trafficking machinery to reach the plasma membrane, traveling through the endoplasmic reticulum and the Golgi apparatus. Given that most GEVIs are based on transgenic sequences, they have not evolved to fold and traffic to the plasma membrane of neurons in commonly used model systems. It is therefore not surprising that membrane localization of the first generation of GEVIs was found to be poor (Baker et al., 2007) and that intensive development efforts are often needed to construct sensors with adequate membrane localization.

Membrane localization of microbial rhodopsins can be improved by the use of endoplasmic reticulum or Golgi export sequences from a voltage-gated ion channel (Gradinaru et al., 2010). However, not all rhodopsins seem to benefit from these motifs; for example, despite the addition of these export tags, the first rhodopsin-based GEVI could be expressed in bacteria but not in mammalian cells (Kralj et al., 2011). Other rhodopsinbased GEVIs containing these export tags can be expressed in mammalian neurons, but their plasma membrane localization remains suboptimal (Gong et al., 2013; Hochbaum et al., 2014). Plasma membrane targeting of GEVIs based on VSDs from voltage-gated ion channels has often been poor (Baker et al., 2007), but using VSDs from voltage-sensitive phosphatases has typically improved membrane localization (Dimitrov et al., 2007; Han et al., 2013). Appending a plasma membrane targeting motif was shown to improve the membrane localization of at least one VSD-based GEVI (Akemann et al., 2012). Additionally, using fluorescent proteins from jellyfish rather than from anemones or corals can reduce intracellular aggregates (Perron et al., 2009; Tsutsui et al., 2013). Membrane localization may be further improved by swapping the opsin or VSD with homologs that naturally target efficiently to the plasma membrane (Kralj et al., 2012) or by optimizing the coupling between the VSD or opsin 


\begin{tabular}{|c|c|c|c|}
\hline $\begin{array}{l}\text { Performance } \\
\text { metrics }\end{array}$ & $\begin{array}{l}\text { Possible } \\
\text { challenges }\end{array}$ & Potential solutions & Selected examples \\
\hline $\begin{array}{l}\text { Plasma membrane } \\
\text { localization }\end{array}$ & $\begin{array}{l}\text { Significant } \\
\text { intracellular } \\
\text { aggregates }\end{array}$ & $\begin{array}{l}\text { Append plasma membrane targeting motifs } \\
\text { Swap VSD/opsin with homologue } \\
\text { Swap fluorescent protein with homologue } \\
\text { Optimize linkers between fluorescent protein and } \\
\text { VSD/opsin } \\
\text { When imaging single cells at high magnification, use } \\
\text { an algorithm to reduce contribution of pixels with } \\
\text { fluorescence that shows poor voltage sensitivity }\end{array}$ & $\begin{array}{l}\text { (Akemann et al., 2012) } \\
\text { (Dimitrov et al., 2007; Kralj } \\
\text { et al., 2012; St-Pierre et } \\
\text { al., 2014) } \\
\text { (Tsutsui et al., 2013; Zou } \\
\text { et al., 2014; Sung et al., } \\
\text { 2015) } \\
\text { (St-Pierre et al., 2014; } \\
\text { Gong et al., 2015) } \\
\text { (Kralj et al., 2012) }\end{array}$ \\
\hline $\begin{array}{l}\text { Toxicity and } \\
\text { perturbation of } \\
\text { wild-type } \\
\text { physiology }\end{array}$ & $\begin{array}{l}\text { Changes in } \\
\text { membrane } \\
\text { excitability }\end{array}$ & $\begin{array}{l}\text { Lower sensor expression level } \\
\text { Reduce number of voltage sensing residues on } \\
\text { VSD } \\
\text { Develop sensors that require less light for high } \\
\text { fidelity imaging } \\
\text { Develop red-shifted GEVIs }\end{array}$ & $\begin{array}{l}\text { n/a } \\
\text { n/a } \\
\text { (Lam et al., 2012; Gong et } \\
\text { al., 2015) } \\
\text { (Kralj et al., 2011; Zou et } \\
\text { al., 2014; Abdelfattah et } \\
\text { al., 2016) }\end{array}$ \\
\hline Brightness & Low brightness & $\begin{array}{l}\text { Swap fluorescent protein with brighter variants } \\
\text { Swap fluorescent protein with better-folding variant } \\
\text { Subject GEVI to directed protein evolution, } \\
\text { screening for improved brightness } \\
\text { Concentrate GEVIs to the subcellular region of } \\
\text { interest }\end{array}$ & $\begin{array}{l}\text { (Tsutsui et al., 2008; Lam } \\
\text { et al., 2012; Gong et al., } \\
\text { 2015) } \\
\text { (St-Pierre et al., 2014) } \\
\text { (Hochbaum et al., 2014; } \\
\text { Abdelfattah et al., 2016) } \\
\text { n/a }\end{array}$ \\
\hline Photostability & Low photostability & $\begin{array}{l}\text { Swap fluorescent proteins with more photostable } \\
\text { variants } \\
\text { Subject GEVI to directed protein evolution, } \\
\text { screening for improved photostability } \\
\text { Develop sensors that are dark in the resting state } \\
\text { When imaging single cells at high magnification, } \\
\text { distribute illumination over a larger section of the } \\
\text { cell by continuously moving the imaging laser } \\
\text { around the membrane } \\
\text { Increase GEVI brightness and reduce illumination } \\
\text { intensity }\end{array}$ & $\begin{array}{l}\text { n/a } \\
\text { n/a } \\
\text { (Kralj et al., 2011) } \\
\text { (Brinks et al., 2015) }\end{array}$ \\
\hline
\end{tabular}

Figure 1. (continued) 


\begin{tabular}{|c|c|c|c|}
\hline Sensitivity & Low sensitivity & $\begin{array}{l}\text { Mutate residues that regulate VSD/opsin voltage } \\
\text { sensitivity } \\
\text { Swap VSD/opsin with homologue } \\
\text { Mutate fluorescent protein to improve its sensitivity } \\
\text { to VSD conformational changes } \\
\text { Optimize the linker between VSD/opsin and } \\
\text { fluorescent protein }\end{array}$ & $\begin{array}{l}\text { (Dimitrov et al., 2007; } \\
\text { Baker et al., 2012; Gong } \\
\text { et al., 2013; Piao et al., } \\
\text { 2015; Abdelfattah et al., } \\
\text { 2016) } \\
\text { n/a } \\
\text { (Jin et al., 2012) } \\
\text { (Dimitrov et al., 2007; St- } \\
\text { Pierre et al., 2014; Zou et } \\
\text { al., 2014; Jung et al., } \\
\text { 2015; Sung et al., 2015; } \\
\text { Abdelfattah et al., 2016; } \\
\text { Yang et al., 2016) }\end{array}$ \\
\hline $\begin{array}{l}\text { Linearity of } \\
\text { fluorescence } \\
\text { response to } \\
\text { voltage }\end{array}$ & $\begin{array}{l}\text { Non-linear } \\
\text { response to } \\
\text { voltage }\end{array}$ & $\begin{array}{l}\text { Test different voltage sensor architectures } \\
\text { If a linear response is observed at voltages beyond } \\
\text { the physiological range, mutate residues to shift the } \\
\text { linear response to the desired voltage range }\end{array}$ & $\begin{array}{l}\text { (Kralj et al., 2011; Barnett } \\
\text { et al., 2012) } \\
\text { n/a }\end{array}$ \\
\hline $\begin{array}{l}\text { Kinetics } \\
\text { voltage } \\
\text { spike }\end{array}$ & Slow kinetics & $\begin{array}{l}\text { Replace VSD/opsin with homologue, in whole or in } \\
\text { part } \\
\text { Optimize coupling between VSD/opsin and } \\
\text { fluorescent protein } \\
\text { Subject GEVI to directed protein evolution, } \\
\text { screening for improved kinetics } \\
\text { Mutate residues that regulate VSD/opsin voltage } \\
\text { sensitivity }\end{array}$ & $\begin{array}{l}\text { (Baker et al., 2012; } \\
\text { Mishina et al., 2012, 2014; } \\
\text { Han et al., 2013; Gong et } \\
\text { al., 2015) } \\
\text { (Jung et al., 2015; Sung et } \\
\text { al., 2015) } \\
\text { (Abdelfattah et al., 2016) } \\
\text { (Gong et al., 2013; } \\
\text { Hochbaum et al., 2014; } \\
\text { Piao et al., 2015; Treger et } \\
\text { al., 2015) }\end{array}$ \\
\hline $\begin{array}{l}\text { Compatibility with } \\
\text { deep-tissue } \\
\text { imaging }\end{array}$ & $\begin{array}{l}\text { Poor performance } \\
\text { under two-photon } \\
\text { illumination }\end{array}$ & $\begin{array}{l}\text { Replace fluorescent proteins with variants that are } \\
\text { brighter and more photostable under two-photon } \\
\text { microscopy } \\
\text { Subject GEVI to directed protein evolution, } \\
\text { screening for improved two-photon performance } \\
\text { Use endoscopes and illuminate with one-photon } \\
\text { excitation } \\
\text { Develop/use red-shifted GEVIs and illuminate with } \\
\text { one-photon excitation }\end{array}$ & $\begin{array}{l}\mathrm{n} / \mathrm{a} \\
\mathrm{n} / \mathrm{a} \\
\mathrm{n} / \mathrm{a} \\
\text { (Kralj et al., 2011; Zou et } \\
\text { al., 2014; Abdelfattah et } \\
\text { al., 2016) }\end{array}$ \\
\hline
\end{tabular}

Figure 1. (continued) 


\begin{tabular}{|c|c|c|c|}
\hline $\begin{array}{l}\text { Measurement of } \\
\text { absolute } \\
\text { membrane } \\
\text { potential }\end{array}$ & $\begin{array}{l}\text { Fluorescence is } \\
\text { not correlated with } \\
\text { absolute } \\
\text { membrane } \\
\text { potential }\end{array}$ & $\begin{array}{l}\text { Calibrate fluorescence responses using a drug that } \\
\text { sets the voltage to a known value } \\
\text { Evaluate fluorescence lifetime imaging for } \\
\text { monitoring absolute voltage } \\
\text { Develop an indicator where the ratio of fluorescence } \\
\text { emission of two fluorescent proteins is correlated } \\
\text { with the absolute membrane potential }\end{array}$ & $\begin{array}{l}\text { (Hoppa et al., 2014) } \\
\text { (Brinks et al., 2015) } \\
\text { n/a }\end{array}$ \\
\hline $\begin{array}{l}\text { Multimodal } \\
\text { interrogation of } \\
\text { brain tissue }\end{array}$ & $\begin{array}{l}\text { Spectral } \\
\text { incompatibility } \\
\text { with optogenetic } \\
\text { reagents or other } \\
\text { biosensors }\end{array}$ & $\begin{array}{l}\text { Develop/use new GEVI color variants } \\
\text { Achieve spectral separation by using two-photon } \\
\text { illumination }\end{array}$ & $\begin{array}{l}\text { (Kralj et al., 2011; Zou et } \\
\text { al., 2014; Abdelfattah et } \\
\text { al., 2016) } \\
\text { (Packer et al., 2015)* }^{*}\end{array}$ \\
\hline $\begin{array}{l}\text { Compatibility } \\
\text { across species }\end{array}$ & $\begin{array}{l}\text { Poor performance } \\
\text { due to differences } \\
\text { in body } \\
\text { temperature } \\
\text { Poor membrane } \\
\text { localization }\end{array}$ & $\begin{array}{l}\text { Develop indicators whose performance is either } \\
\text { optimized for the desired temperature or robust } \\
\text { across a range of temperatures } \\
\text { Use plasma targeting sequences from the species } \\
\text { of interest, if known }\end{array}$ & n/a \\
\hline
\end{tabular}

Figure 1. GEVI performance metrics and challenges. Each table row presents an important criterion for evaluating sensor performance. For each criterion, one or more possible challenges are listed, along with potential solutions that could address the corresponding challenge. The selected examples cite articles that illustrate the solutions, regardless of effects on other performance metrics. *This solution was demonstrated with a GFP-based GECI but may be extended to GFP-based GEVIs.

and the fluorescent protein(s) (St-Pierre et al., 2014; Gong et al., 2015). Given that membrane targeting efficiency can be lower in vivo than in vitro (Gong et al., 2015), new indicators should ideally be tested in both contexts.

\section{Toxicity and perturbation of wild-type physiology}

Another challenge of voltage imaging is to develop sensors and imaging modalities that minimally perturb cellular function. In particular, insertion of GEVIs could affect the excitability of the plasma membrane, for example, by increasing membrane capacitance. A theoretical analysis of the effect of a prototypical VSDbased GEVI on neuronal excitability suggests that the presence of GEVIs in the membrane can reduce the amplitude of EPSPs and increase action potential initiation thresholds (Akemann et al., 2009). Expression of a VSD-based GEVI in flies was found to modestly increase membrane capacitance and decrease the action potential maximal rise slope (Cao et al., 2013). Other characteristics, such as the resting membrane potential and the amplitude and initiation threshold of action potentials, were not significantly affected. Studies with other indicators and in other experimental systems did not detect a significant change in cellular capacitance (Hochbaum et al., 2014; St-Pierre et al., 2014) or in action potential duration and amplitude (Jin et al., 2012; Gong et al., 2015) in neurons under experimentally relevant expression levels. The effects of GEVIs on cellular physiology likely vary based on the target neuron, expression levels, and GEVI properties. It is thus important to carefully evaluate the impact of GEVI expression on neuronal excitability when using a new GEVI or experimental system.

Another concern is that the illumination required for exciting GEVIs can damage cells over time. This phototoxicity is a critical consideration, particularly if the duration of continuous illumination is long or if the same cells are reimaged periodically over weeks or months. Visible light absorption by cellular material itself can cause changes in cell morphology (Tan et al., 2010) and DNA integrity (Pflaum et al., 1998; Godley et al., 2005). Illumination of cells expressing fluorescent proteins has been observed to alter growth rate (Carlton et al., 2010), cell cycle progression (Dixit and Cyr, 2003), and cell morphology (Magidson and Khodjakov, 2013), likely via the formation of reactive oxygen species (Dixit and Cyr, 2003).

Lower phototoxicity can be achieved by decreasing the illumination intensity required to detect the signal of interest, by using GEVIs that respond to voltage transients with a larger signal-tonoise ratio, and by leveraging powerful denoising algorithms (Carlton et al., 2010). Shorter wavelengths, in particular blue light, tend to cause more damage because of their higher energy and the presence of blue light-absorbing chromophores in many biological tissues (Magidson and Khodjakov, 2013). Phototoxicity can therefore be minimized by exciting with light of longer wavelengths (Magidson and Khodjakov, 2013). GEVIs with redshifted excitation spectra have been developed, although their lower brightness (Kralj et al., 2011) or sensitivity (Abdelfattah et al., 2016) can require higher illumination power to obtain equivalent signal-to-noise ratios to the highest-performing blueshifted GEVIs. It is therefore unclear whether experiments with these indicators would actually produce less phototoxicity.

\section{Brightness and photobleaching}

Ideal GEVIs should also be bright and photostable. To report fast electrical events, such as action potentials, GEVIs must produce enough photons to be detected above noise on a millisecond 
timescale over the minutes or hours of an experiment. Because of the kinetics of the indicators and the signals they are monitoring, voltage imaging is typically performed at higher frame rates than calcium imaging. Faster acquisitions result in fewer photons captured per frame, which can be compensated for by increased indicator brightness or higher illumination intensity. However, higher illumination intensities cause greater photobleaching and phototoxicity. Moreover, when imaging under laser-scanning microscopy, photobleached GECI molecules may be replaced by cytoplasmic diffusion of probes from nonilluminated areas within the same cell, but slower diffusion in lipid membranes (Fujiwara et al., 2016) limits the speed at which bleached GEVI molecules can be replaced. Compared with calcium imaging, voltage imaging therefore places greater demands on indicator brightness and photostability.

GEVIs differ significantly in their intrinsic brightness. Despite impressive engineering efforts to improve their brightness, GEVIs in which an opsin is the fluorescent molecule remain approximately two orders of magnitude dimmer than GEVIs with fluorescent proteins and are thus likely too dim for many in vivo experiments (Flytzanis et al., 2014; Hochbaum et al., 2014; McIsaac et al., 2014). To increase brightness, these GEVIs can be converted into FRET sensors by fusing the opsin to a bright donor fluorescent protein; typically, only emission from the donor fluorescent protein is monitored, given its much higher fluorescence compared with the opsin acceptor domain (Gong et al., 2014; Zou et al., 2014). While the kinetics and sensitivity of these initial sensors were impaired compared with the standalone opsin domain, a recent study reported a FRET-opsin sensor that has submillisecond kinetics but lower sensitivity (Gong et al., 2015). Several VSD-based sensors are based on circularly permuted fluorescent proteins, which have $\mathrm{N}$ - and C-termini closer to the chromophore (Baird et al., 1999). However, circular permutation reduces fluorescence, and further mutagenesis is often needed to reestablish parental brightness (Abdelfattah et al., 2016). More simply, the brightness of some VSD-based and FRET-opsin sensors can be improved by swapping the fluorescent proteins for brighter variants (Tsutsui et al., 2008; Lam et al., 2012; Gong et al., 2015). However, improved brightness can come at the expense of other properties, such as photostability under laser illumination (Shaner et al., 2013) and membrane localization in neurons (Perron et al., 2009).

In addition to GEVIs' intrinsic brightness, cellular factors may also influence GEVI brightness at the imaged membrane. These include expression level, efficiency of membrane targeting, turnover rates due to endocytosis or degradation, and indicator distribution across the different subcellular regions of a neuron. Controlling some of these factors may present an alternate route for improving effective brightness. For example, targeting motifs could be used to restrict GEVIs to specific subcellular areas, such as the soma or dendrites (Lai and Jan, 2006; Grubb and Burrone, 2010), thus increasing the per-pixel brightness of those regions. However, concentrating GEVI molecules will locally increase capacitance and may significantly disturb neuronal physiology, as discussed in Toxicity and perturbation of wild-type physiology.

GEVI photostability is critical to enable voltage imaging over minutes or hours. However, all GEVIs show a significant decrease in fluorescence after several seconds or minutes of illumination, with photobleaching time constants depending on the indicator and the illumination conditions (Hochbaum et al., 2014; Brinks et al., 2015; Abdelfattah et al., 2016). In contrast, a recent GFPbased GECI showed minimal photobleaching after 5 min of con- tinuous illumination during imaging of dendritic spines in the visual cortex of awake mice (Chen et al., 2013). GEVIs based on opsin fluorescence, although intrinsically less bright, are typically more photostable under widefield illumination than those based on fluorescent proteins (Hochbaum et al., 2014).

GEVIs have yet to be directly evolved and screened for improved photostability. Of note, the brightness and photostability of fluorescent proteins and GEVIs can differ based on illumination conditions, including light source (e.g., halogen lamp, onephoton laser, or two-photon laser), intensity, wavelength, and time-varying modulation (Shaner et al., 2005; Dean et al., 2011). For example, a recently reported bright GFP variant has a photostability comparable with EGFP under widefield arc illumination, but it is $40 \%$ as photostable under laser illumination (Shaner et al., 2013). A GEVI was also observed to exhibit spontaneous brightness fluctuations unrelated to neural activity under some illumination conditions but not others (Kibat et al., 2016). This variability further complicates the development of fluorescent indicators that are photostable under different illumination conditions and the comparison of probes benchmarked using different photobleaching protocols. Furthermore, mutations that improve brightness and photostability may also affect GEVI kinetics, sensitivity, or both (Hochbaum et al., 2014; St-Pierre et al., 2014). Further development would thus benefit from simultaneous monitoring of all these GEVI performance metrics across a range of standardized illumination conditions.

As some pathways to photobleaching are thought to depend on the fluorophore being in its excited state (Dean et al., 2011), another strategy to improve photostability is to engineer voltage indicators that are dark in the resting state and become brighter upon depolarization. Indeed, unlike the GCaMP/RCaMP and GECO series of calcium indicators, many of the most sensitive GEVIs become dimmer upon depolarization (Nakai et al., 2001; Zhao et al., 2011; St-Pierre et al., 2015). The main exceptions are GEVIs based on standalone fluorescent opsins. However, it is important to consider that GEVIs that are too dark when the cell is at its resting membrane potential will require additional fluorophores to help experimenters detect GEVI-expressing neurons. Decreased sensor brightness during hyperpolarizations may also be challenging to monitor for GEVIs that are already very dim at the resting membrane potential.

In addition to directly improving indicator properties, modulating imaging parameters can increase the effective photostability. For example, it was suggested that GEVI photostability under laser-scanning microscopy could be improved by distributing light over many membrane pixels by continuously moving the laser beam around the cell membrane (Brinks et al., 2015). This strategy may be used when imaging single cells under high magnification but may be difficult to implement when imaging larger populations of cells at lower magnification.

\section{Sensitivity}

A critical parameter when evaluating GEVIs is their sensitivity (also known as dynamic range), defined here as the steady-state change in fluorescence in response to a voltage step within the physiological range. Overall, GEVI sensitivity remains small. For a depolarization from -70 to $30 \mathrm{mV}$ measured under onephoton illumination, the most sensitive GEVI based on a single fluorescent protein showed a steady-state fluorescence decrease of $\sim-35 \%$ (Jin et al., 2012), compared with a maximal theoretical value of $-100 \%$. The most sensitive GEVI based on opsin fluorescence showed an increase of $\sim 90 \%$ (Hochbaum et al., 2014). The maximal sensitivity for these sensors is theoretically 
infinite, although it is limited in biological contexts by several factors, including residual fluorescence in the dark state and cellular autofluorescence.

Sensitivity of opsin-based sensors can be improved by sitedirected mutagenesis of residues implicated in their photocycle (Gong et al., 2013; Park et al., 2013; Hochbaum et al., 2014) or, for FRET-opsin sensors, by screening several possible fluorescent protein donors or opsin acceptors (Gong et al., 2014; Zou et al., 2014). For VSD-based indicators, sensitivity can be improved by mutating the fluorescent protein (Jin et al., 2012), the VSD (Dimitrov et al., 2007; Baker et al., 2012; Piao et al., 2015; Abdelfattah et al., 2016), or the linkers coupling the VSD to the fluorescent protein (Dimitrov et al., 2007; St-Pierre et al., 2014; Zou et al., 2014; Jung et al., 2015; Sung et al., 2015; Abdelfattah et al., 2016; Yang et al., 2016). Replacing the VSD or the fluorescent proteins with homologs can also affect sensitivity (Baker et al., 2012; Han et al., 2013; St-Pierre et al., 2014). We anticipate that further protein engineering using these strategies will continue to improve GEVI sensitivity.

While greater sensitivity tends to increase GEVI performance, sensitivity is not the sole determinant and must be considered along with other performance metrics. In particular, under typical imaging regimens, the detectability of a voltage transient will also depend on indicator brightness and kinetics (Wilt et al., 2013). It is therefore improper to directly compare the sensitivity of dark-to-bright and bright-to-dark sensors without considering their respective starting fluorescence levels. Similarly, a high sensitivity indicator will be of limited value if its kinetics are significantly slower than the timescale of the electrical activity that the GEVI is meant to monitor. Therefore, sensitivity, kinetics, and brightness should be considered together when benchmarking the ability of a GEVI to detect a specific type of neuronal electrical event and should be optimized together during GEVI development.

\section{Linearity of fluorescence response to voltage}

In the previous section, we discussed the importance of the steepness of the relationship between voltage and fluorescence, which we call sensitivity. Whether this relationship is linear or nonlinear can be an important characteristic by itself, regardless of the overall sensitivity. A linear relationship between voltage and fluorescence results in optical traces that more closely resemble the underlying voltage transients and is thus important when highfidelity reporting of voltage waveforms is critical. However, a linear response is not optimal for all experiments. For example, when monitoring voltage dynamics under conditions where photons are severely limited (e.g., when imaging large populations of cells in vivo with millisecond-timescale resolution), the signal-tonoise ratio may be insufficient for reliably distinguishing action potentials from large subthreshold depolarizations. Action potential counting would therefore be facilitated by a sensor with minimal responses below the action potential threshold potential and large responses above this threshold.

Opsin-based sensors generally produce linear responses (Kralj et al., 2011). Some VSD-based sensors also produce linear responses (Barnett et al., 2012; Abdelfattah et al., 2016), whereas others produce responses that are either sigmoidal (Dimitrov et al., 2007; Jin et al., 2012) or otherwise nonlinear (St-Pierre et al., 2014). Response linearity thus depends on GEVI architecture but could presumably be affected by mutating residues involved in voltage sensing.

\section{Kinetics}

For high-fidelity monitoring of voltage dynamics, GEVIs must have kinetics that match or surpass those of the transients they are reporting. Several current GEVIs based on VSDs or opsins have met this challenge, boasting kinetics with millisecond or even submillisecond time constants (Gong, 2015; Gong et al., 2015; Knöpfel et al., 2015; St-Pierre et al., 2015). Some fast GEVIs were developed from previous variants by replacing their VSDs or opsin domains with orthologs (Baker et al., 2012; Han et al., 2013; Gong et al., 2015) or by replacing a section of the VSD with a homologous fragment from a fast voltage-gated potassium channel (Mishina et al., 2012, 2014). Faster kinetics were also achieved by rational (Gong et al., 2013; Piao et al., 2015; Treger et al., 2015) or random (Abdelfattah et al., 2016) mutagenesis and by optimizing coupling between the VSD and fluorescent protein(s) (Jung et al., 2015; Sung et al., 2015).

The combination of kinetics and sensitivity determines the relative fluorescence change in response to a voltage transient. The highest reported fluorescence changes by GEVIs to single action potentials are $\sim 50 \%$ (in vitro) and $\sim 3 \%$ (in vivo, mice), monitored with different indicators (Hochbaum et al., 2014; Gong et al., 2015). In comparison, recent GECIs produced $\sim 25 \%$ (in vitro) and $\sim 23 \%$ (in vivo, mice) responses to single action potentials (Chen et al., 2013). Detection of sparse action potentials with GECIs is further facilitated by the longer-lasting fluorescence responses of calcium indicators, which allows for longer integration times. However, because of the slow dynamics of both the calcium indicator (Chen et al., 2013; Badura et al., 2014) and the calcium transients themselves (Helmchen et al., 1996; Koester and Sakmann, 2000), resolving action potentials that are closely spaced in time will typically require GEVIs rather than GECIs.

\section{Compatibility with deep-tissue imaging techniques}

As a result of light scattering and absorption, imaging with linear (one-photon) illumination is typically limited to $\sim<100 \mu \mathrm{m}$ below the tissue surface (Helmchen and Denk, 2005), with redshifted wavelengths typically enabling deeper imaging. Endoscopy overcomes imaging depth limits by using a series of small lenses and fiber optics to physically provide access to deeper regions (Wilt et al., 2009); however, it damages overlying brain tissue. In contrast, two-photon microscopy, a nonlinear illumination technique, permits imaging down to $\sim 1 \mathrm{~mm}$ below the brain surface and can be less phototoxic than other techniques (Helmchen and Denk, 2005; Svoboda and Yasuda, 2006).

Because of these useful properties, two-photon microscopy has established itself as a key method for deep-tissue imaging of neural activity using GECIs. Two-photon imaging of single neurons in vivo has also been demonstrated for a few GEVIs but achieving adequate signal-to-noise ratios required multitrial averaging or slow $(\leq 100 \mathrm{~Hz})$ acquisition speeds, or both (Ahrens et al., 2012; Akemann et al., 2013; Storace et al., 2015; Yang et al., 2016). There are several challenges with two-photon illumination of GEVIs. First, performance metrics of GEVIs under twophoton excitation are not always predictable from their onephoton properties. For example, while two different VSD-based GEVIs showed similar sensitivity under one- and two-photon illumination, three GEVIs based on opsins produced drastically lower fluorescence responses under two-photon excitation (Brinks et al., 2015). Second, maximal photon emission rates are lower with two-photon than with one-photon microscopy (Svoboda and Yasuda, 2006). Finally, while fluorophore photobleaching rates under one-photon excitation usually vary linearly with illumination intensity, photobleaching increases supralinearly with 
two-photon excitation power (Patterson and Piston, 2000; Chen et al., 2002). Together, these observations motivate development of GEVIs that are specifically optimized for two-photon excitation.

Two-photon imaging of voltage activity over larger areas is also challenging. Coupled with resonant scanners, two-photon laser scanning microscopy can image a $512 \times 512$ pixel area at 30 $\mathrm{Hz}$, a frame rate typically sufficient for following calcium dynamics but usually inadequate for monitoring fast voltage transients, such as action potentials. The imaged area would need to be decreased by 32 - to 64 -fold to achieve adequate frame rates, severely limiting the number of neurons or subcellular areas that can be observed in the same experiment. However, several strategies have been reported to increase scanning speed by dividing the beam in space or time, as reviewed by Carriles et al. (2009). Another exciting strategy is to restrict imaging exclusively to voxels of interest, using acousto-optic deflection to rapidly move the laser between preselected positions in 3D (Duemani Reddy et al., 2008). This technology, called $3 \mathrm{D}$ random access multiphoton imaging, has been reported to enable imaging of $\sim 50,000$ points per second, suggesting it could be used to follow up to $\sim 50$ neurons with $1 \mathrm{kHz}$ temporal resolution (Katona et al., 2012; Cotton et al., 2013). An important drawback to using this technology in vivo, however, is its high sensitivity to motion of the imaged tissue; this limitation may be exacerbated by the need for greater positional stability when imaging membrane-localized GEVIs instead of cytoplasmic GECIs. Another promising technology is two-photon light-sheet microscopy, which combines the high acquisition speed of light-sheet imaging with the excellent penetration depth of two-photon illumination (Truong et al., 2011; Wolf et al., 2015). While traditional light-sheet imaging cannot easily image neural activity in live mice due to constrained sample geometry, a new microscopy technique has recently enabled light-sheet imaging in awake, behaving mice with one-photon excitation and may be extendable to two-photon illumination (Bouchard et al., 2015). However, uneven illumination power throughout the sheet would result in varying signal-to-noise ratios and photobleaching rates. Moreover, readout rates of commercially available cameras limit the imaged area to a subset of the sensor's pixels when acquiring with millisecond-timescale resolution. We look forward to further optimization of these technologies and to the development of new methods to image neural tissue faster, deeper, and more evenly.

\section{Measurement of absolute membrane potential}

To best interpret GEVIs' readout, it would be useful to directly relate fluorescence to the absolute membrane potential. Voltage sensors could in principle encode absolute membrane potential in the emission ratio of two fluorescent proteins, but this strategy has not yet been demonstrated. Moreover, ratiometric imaging is predicted to have lower signal detection fidelity than single-color imaging when the two emission channels are asymmetric in their brightness, signal amplitudes, or both (Wilt et al., 2013).

Another approach is to calibrate GEVI responses by comparing the fluorescence changes induced by the voltage signals of interest to that induced by bringing the cell to a known potential, for example, by using a chemical compound that destroys the ion gradient to bring the cell to $0 \mathrm{mV}$ (Hoppa et al., 2014). This approach is generalizable to other indicators but may be difficult to apply in vivo.

In an alternate strategy, an opsin-based GEVI's response to a change in illumination wavelength was used to measure absolute voltage with $\sim 10 \mathrm{mV}$ accuracy (Hou et al., 2014b). However, the optimal illumination protocol lasted 1-2 s per image, making this approach suitable for static measurements but too slow for capturing fast time-varying voltage signals. Moreover, this strategy required averaging measurements over an entire cell and is therefore not suitable for experiments requiring subcellular resolution. Finally, this method required a complex multiwavelength optical setup. In a second study, two-photon fluorescence lifetime imaging of another opsin-based GEVI was found to encode absolute voltage with $\sim 20 \mathrm{mV}$ accuracy but again required long (1 s) measurements and did not achieve subcellular resolution (Brinks et al., 2015). As in the previous method, measurements were made using cells from an immortalized cell line; its validity for measuring absolute voltage in neurons, both in vitro and in vivo, remains to be demonstrated. Further engineering efforts will be required to develop reporters of absolute membrane potential that are more broadly applicable. Nevertheless, the studies discussed above are impressive first demonstrations that pave the way for further research on absolute membrane potential imaging.

\section{Multimodal interrogation of brain tissue}

An exciting prospect in voltage imaging is the ability to combine GEVIs with other optical tools. In particular, the ability to combine GEVIs with optogenetics (Boyden et al., 2005) would enable all-optical interrogation of neural circuits (for review, see Emiliani et al., 2015). Hochbaum et al. (2014) demonstrated that a far red opsin-based GEVI could be used simultaneously with a blueabsorbing channelrhodopsin in vitro. Given the low brightness of the GEVI, this approach has not yet been extended to in vivo preparations. Another combination paired blue-absorbing channelrhodopsins with a red VSD-based GEVI (Abdelfattah et al., 2016). However, the GEVI was found to undergo photoactivation under blue light excitation, illustrating the need to carefully evaluate spectral cross-talk when considering multimodal experiments. A prospective strategy would be to combine greenemitting indicators with red-shifted opsins under two-photon illumination, but this combination has only been reported for GECIs (Packer et al., 2015) and not for GEVIs.

Beyond simultaneous voltage readout and manipulation, GEVIs could also be used with indicators of other modalities. For example, voltage and calcium were simultaneously monitored in the zebrafish heart (Hou et al., 2014). Other indicators that could be paired with GEVIs for multimodal interrogation of brain tissue include sensors of neurotransmitters, $\mathrm{pH}$, small-molecule metabolites, and enzymatic activity (Ibraheem and Campbell, 2010; Tantama et al., 2012; Broussard et al., 2014; Hochreiter et al., 2015).

\section{Compatibility across species}

The final performance criterion reviewed here is the ability of GEVIs to report voltage signals in key model systems used in neuroscience. There are a number of demonstrations of GEVIbased voltage imaging in flies and mice (see Deploying GEVIs). Two recent studies show that GEVIs can also detect voltage changes in worm (Flytzanis et al., 2014) and zebrafish (Kibat et al., 2016) neurons, although further work will be needed to establish whether the performance of current GEVIs in these organisms is sufficient for addressing biological questions. Indeed, the ability of a GEVI to report voltage in one species does not guarantee its expression or performance in another species. For example, a GEVI known to function in mice and flies could not be expressed in zebrafish neurons (Kibat et al., 2016). Reduced expression may result from silencing of the GEVI transgene or differences in how integral membrane proteins fold or are targeted to the plasma membrane. Membrane lipid composition 
may also affect GEVI performance (Zheng et al., 2011). Additionally, temperature has been shown to affect the kinetics of both opsin-based (Maclaurin et al., 2013) and VSD-based indicators (Lundby et al., 2010). Given the different body temperatures of the key model systems, GEVI performance would thus be expected to vary accordingly. Broader use of GEVIs would benefit from a more systematic characterization of the performance of current and future indicators across model systems.

\section{Deploying GEVIs}

The promise of any new technique is its ability to enable experiments that address previously unanswerable biological questions. Here, we discuss a few types of neurobiological questions we believe GEVIs are especially well suited to address, both those that are currently accessible with the latest generation of indicators and those that will require additional sensor optimization.

\section{How do networks of neurons compute on rapid timescales?}

Many neurobiologists dream of using GEVIs to monitor action potentials across networks of tens, hundreds, or thousands of individual neurons in vivo as an animal is experiencing a sensory stimulus or performing a behavioral task. However, as discussed above, current GEVIs have less sensitivity to action potentials in vivo compared with GECIs; they also require $\sim 100$-fold faster imaging. Under the same experimental conditions, obtaining comparable signal-to-noise ratios as GECIs would therefore require an excitation power that is orders of magnitude higher, resulting in greater phototoxicity and rapid photobleaching. Rapid imaging of large fields of view is also limited by imaging hardware, making it improbable that $>\sim 50$ cells could be imaged with millisecond-timescale resolution. Given these limitations in indicator performance and imaging technology, GEVIs have so far enabled imaging of separate signals from no more than a few individual neurons simultaneously in vivo (Fig. 2A) (Cao et al., 2013; Gong et al., 2015; Sitaraman et al., 2015). As such, the extension to hundreds or thousands of neurons in vivo is likely to require drastic improvements in GEVI imaging wetware and hardware.

Nevertheless, simultaneously measuring action potentials in many individual neurons is by no means the only type of biologically informative experiment examining networks of neurons. GEVIs have been used to monitor voltage changes with $\sim 5-30$ $\mu \mathrm{m}$ lateral resolution over several square millimeters of cortex in awake mice (Akemann et al., 2012, 2013; Scott et al., 2014; Carandini et al., 2015; Madisen et al., 2015; for review, see Knöpfel et al., 2015; Antic et al., 2016). For example, imaging a GEVI targeted to layer $2 / 3$ cortical pyramidal neurons, Scott et al. (2014) tested theoretical predictions on how spontaneous electrical activity is coordinated at different spatial scales. Importantly, GEVI imaging allowed the authors to examine the coordination of electrical activity over four orders of magnitude of spatial scale, a range inaccessible to a single electrophysiological technique.

Large-scale GEVI imaging has also been used to measure somatosensory responses and to construct maps of cortical retinotopy and tonotopy and of temporal heterogeneity across olfactory bulb glomeruli (Fig. 2B) (Akemann et al., 2013; Carandini et al., 2015; Madisen et al., 2015; Storace et al., 2015). Imaging odor-evoked voltage responses in the olfactory bulb, Storace et al. (2015) recapitulated previous observations that temporal properties are spatially organized along the caudal-lateral to rostral-medial axis. Importantly, they also demonstrated that they were able to distinguish activity from individual odorant inhalations by voltage but not by calcium imaging (Storace et al., 2015).
Given that GEVIs are currently capable of, and uniquely suited for, measuring large-scale voltage dynamics, we anticipate exciting new studies addressing more biological questions. For example, the studies described above examined cortical layer $2 / 3$ pyramidal cells and olfactory bulb mitral and tufted cells, which are all excitatory; it would be interesting to compare these responses with those of other cell types, especially inhibitory neurons. Large-scale GEVI imaging could also be used to study whether there are changes in coordinated activity across the cortex throughout development or in disease. Finally, with spectrally compatible indicators, the relationship between two different signals (the voltage responses of two distinct cell types or voltage and calcium responses) could be measured. As technology advances, we expect imaging of voltage dynamics across neural networks to achieve greater spatiotemporal resolution, thereby enabling increasingly powerful studies of circuit computation.

\section{How do single neurons transform information?}

Single neurons are powerful computational units. Studies of dendritic integration have demonstrated that, through active spikes and passive filtering, dendritic trees perform computations, such as logical operations (e.g., AND, OR, and AND-NOT) and summation (for review, see London and Häusser, 2005; Stuart and Spruston, 2015). Furthermore, axon terminals are also sites of information processing. For example, presynaptic plasticity acting on timescales of milliseconds to minutes has been proposed to enable computations, such as adaptation, decorrelation, and filtering (Abbott and Regehr, 2004).

Studies of signal transformations within individual neurons have typically used electrophysiological approaches or calcium imaging. However, it is technically challenging to perform electrode recordings from more than one or two different spatial locations simultaneously within the same neuron, and these recordings are generally limited to cell bodies and large-caliber neurites. Although calcium imaging enables access to many more subcellular regions, it provides only an indirect and imperfect readout of voltage dynamics. It also lacks the temporal resolution to examine the precise coordination of signals. By overcoming these limitations, GEVIs are well positioned to enable breakthrough experiments examining information processing in single neurons.

GEVIs have been used to map the dynamics of backpropagating action potentials in vitro and in vivo. In vitro, GEVI imaging, combined with subframe temporal interpolation and multitrial averaging, enabled the propagation of action potentials from the site of initiation in the axon initial segment back into the soma and dendrites to be mapped with submillisecond temporal resolution and $\sim 2 \mu \mathrm{m}$ spatial resolution (Fig. $2 C$ ) (Hochbaum et al., 2014). In vivo, GEVI imaging allowed the delay in the arrival of a backpropagating action potential among dendritic branches to be measured in both mice and flies after averaging over multiple trials (Gong et al., 2015).

Using GEVI imaging in vitro, Hoppa et al. (2014) demonstrated for the first time that potassium channels cause the peak amplitude of the action potential at the axon terminal to be smaller than that at the soma (Fig. 2D). This study further showed that the shape of this presynaptic action potential can be modulated, likely to maintain the neuron's ability to release synaptic vesicles following changes in the abundance of key voltage-gated ion channels.

More recently, sensory stimulus-evoked signals in Drosophila visual interneurons in vivo were monitored using two-photon imaging of both GEVIs and GECIs (Yang et al., 2016). This study demonstrated that voltage waveforms were conveyed with high fidelity through the lengths of these neurons, but calcium responses were 
A

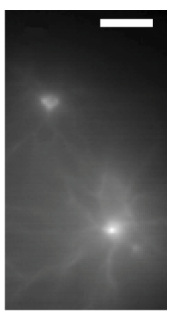

C

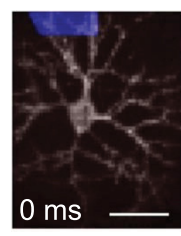

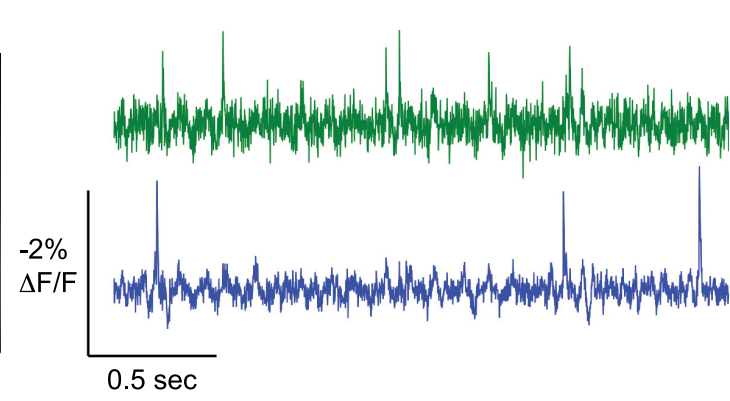

B

Azimuth (deg)

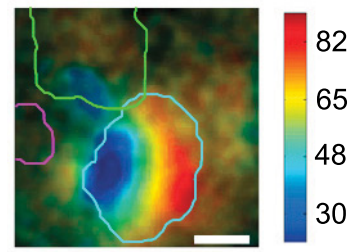

Elevation (deg)
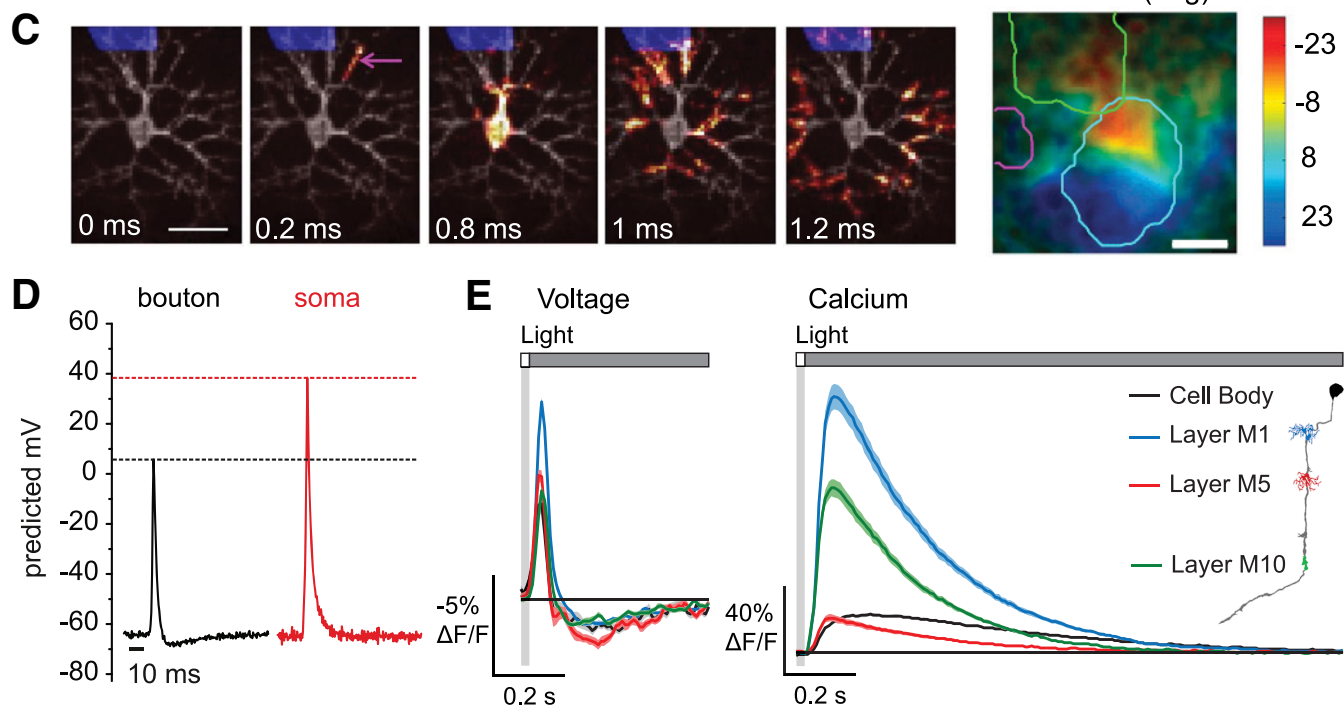

$\mathbf{F}$

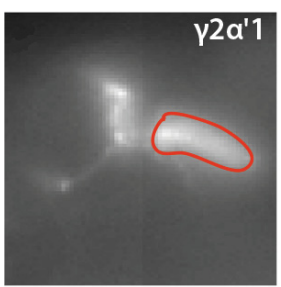

non-deprived
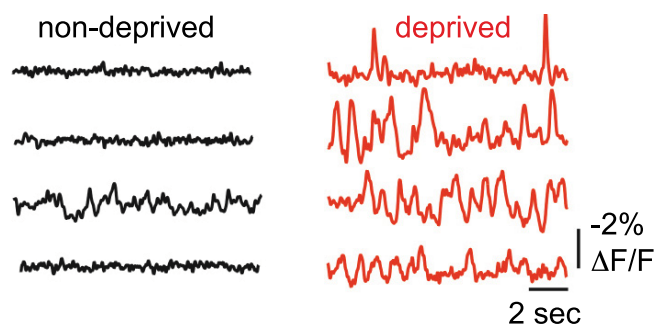

Figure 2. Applications of GEVIs across experimental systems. A, Simultaneous single-trial recordings of action potentials from two neurons in cortical area V1 of an awake mouse. Cells were illuminated with light-emitting diodes (LEDs) at a power density of $25 \mathrm{~mW} / \mathrm{mm}^{2}$ and imaged at $1 \mathrm{kHz}$ using a scientific complementary metal-oxide semiconductor camera. Scale bar, $40 \mu \mathrm{m}$. Adapted with permission from Gong et al. (2015). B. Retinotopic maps from wide-field imaging of cortical layer 2/3 neurons in an awake mouse in response to $2 \mathrm{~Hz}$ flickering visual stimuli. Top, Stimulus azimuth response map. Bottom, Stimulus elevation response map. Responses to each stimulus were averaged over 20 trials. Scale bar, $1 \mathrm{~mm}$. The brain was illuminated with an LED and photons were collected at $50 \mathrm{~Hz}$ using a scientific complementary metal oxide semiconductor camera. Contour lines indicate the boundaries of the visual cortex (blue), barrel cortex (green), and auditory cortex (pink). Adapted with permission from Madisen et al. (2015). C, Action potential backpropagation in a cultured rat hippocampal neuron. Illumination was performed with a laser at a power density of $3000 \mathrm{~mW} / \mathrm{mm}^{2}$. Fluorescence was collected at $1 \mathrm{kHz}$ using an electron multiplying charge-coupled device. Subframe interpolation was used to infer submillisecond timing from image sequences averaged over 203 action potentials. Scale bar, $50 \mu \mathrm{m}$. Adapted with permission from Hochbaum et al. (2014). D, Action potentials recorded from a presynaptic bouton and the soma of the same cultured hippocampal neuron. Action potential amplitude was calibrated by comparing the fluorescence change elicited by an action potential with the fluorescence change elicited by application of gramicidin, which brought the resting membrane potential to $0 \mathrm{mV}$. Traces were averaged over 9 cells, 400 trials per cell. Neurons were illuminated with a laser at a power density of $\sim 22,500 \mathrm{~mW} / \mathrm{mm}^{2}$, with fluorescence captured at $2 \mathrm{kHz}$ using an electron multiplying charge-coupled device. Adapted with permission from Hoppa et al. (2014). $\boldsymbol{E}$, In vivo voltage (left) and calcium (right) signals recorded across subcellular regions of the Drosophila visual interneuron $\operatorname{Im} 3$ in response to $25 \mathrm{~ms}$ flashes of light off of a gray background. Cells were imaged with two-photon laser scanning microscopy at a frame rate of $38.9 \mathrm{~Hz}$ that was upsampled during analysis to $120 \mathrm{~Hz}$. Power was $\sim 10 \mathrm{~mW}$ at the sample plane. Response traces for each region are mean $\pm 1 \mathrm{SEM}$ averaged over 13-158 cells, 100 trials per cell for voltage, 50 trials per cell for calcium. Adapted with permission from Yang et al. (2016). F, Single-trial spontaneous electrical activity recorded in the dendrites of sleep-promoting $\gamma 2 \alpha^{\prime} 1$ cells in acute brain explants from sleep-deprived and nondeprived Drosophila. Cells were illuminated with an LED and fluorescence captured at a frame rate of $125 \mathrm{~Hz}$ using a charge-coupled device. Adapted with permission from Sitaraman et al. (2015).

compartmentalized across arbors in a manner that could support differential local signaling (Fig. 2E). Additionally, the selectivity for either light or dark visual stimuli observed in these interneurons was found to arise from the transformation between membrane potential and intracellular calcium concentration.

Expanding on these experiments, future work is poised to use GEVIs to provide greater insight into computations by single neurons. We do note, however, that in all of the studies discussed here, significant averaging over 200-17,000 trials was used to achieve the reported signals. Single-trial monitoring of subcellular voltage dynamics with submillisecond resolution is currently beyond the performance of current indicators and would require faster imaging methods.

Despite this limitation, previously unanswerable questions can still be addressed, and further technological improvements in the near future will open the door to more questions. For exam- 
ple, one could quantitatively examine how factors such as dendritic morphology and ion channel expression influence action potential backpropagation. Another critical open question is the spatial distribution of synaptic inputs: do inputs carrying similar information converge onto the same or different dendritic branches, and how does that distribution shape how those inputs are transformed? How do different dendritic tree morphologies influence the distribution and transformation of inputs? Axon terminals are sometimes underappreciated as sites of neuronal computation, but GEVIs can enable the function of axonal voltage dynamics and presynaptic plasticity to be examined with unprecedented resolution. Finally, in vivo studies with GEVIs will allow one to ask how signal transformations within individual neurons extract behaviorally relevant information.

\section{Final thoughts on using GEVIs for biological discovery}

In the previous subsections, we discussed two classes of biological questions that GEVIs are uniquely suited to address. More generally, as optical sensors, GEVIs enable voltage recordings that are difficult to achieve with other techniques. In particular, GEVIs allow voltage signals in small neurons and subcellular regions other than the soma to be recorded. These advantages have been leveraged in studies with Drosophila, which has small neurons and where critical information processing steps are thought to occur in presynaptic and postsynaptic neurites. For example, Sitaraman et al. (2015) used GEVI imaging to measure electrical activity in Drosophila mushroom body output neuron dendrites and Kenyon cell axons and identified new sleep-promoting and wake-promoting cells and microcircuits (Fig. $2 F$ ). The same group has also recorded voltage changes in Drosophila olfactory and circadian neurons (Cao et al., 2013). Patch clamping Caenorhabditis elegans neurons is also difficult because they are small with a high membrane resistance and because they can only be accessed by puncturing a touch cuticle (Nickell et al., 2002); as a result, electrophysiological recordings have only been achieved from a few of its 118 neuron classes (Lockery and Goodman, 2009). High-performing GEVIs would therefore be particularly useful as an alternative technique for measuring the voltage signals of $C$. elegans neurons. Additionally, even in systems where electrophysiology is possible and well established, GEVIs could allow greater experimental throughput, a necessity for studies where variability or the number of groups to be examined is large. Such experiments include recordings from induced pluripotent stem cell-derived neurons (Hochbaum et al., 2014) or smallmolecule drug screens (Zhang et al., 2016).

\section{Future perspectives}

GEVIs leverage the advantages of light and genetics to track neuronal voltage dynamics. There has been tremendous progress in GEVI development over the last few years, producing more distinct indicator designs than for any other class of fluorescent biosensors. Of the current generation of GEVIs, the bestperforming indicator will depend on the specific experimental system, including the imaging modality (one-photon vs twophoton), model system, kinetics of the electrical events of interest, and spatial resolution. We anticipate swift progress toward developing indicators that improve optical detection of neural electrical activity, extending their usefulness in vitro and in vivo.

The impressive protein engineering efforts are motivated by the potential for GEVIs to enable critical new experiments. Some questions, such those requiring simultaneous measurement of the electrical activity of large numbers of individual neurons in vivo, will require important improvements to both the indicator and the imaging technology. Other studies, such as those examining signal processing within single neurons, are beginning to be accessible by current technology. Creative thinking will undoubtedly lead to new GEVI-powered experiments we have not considered here. We look forward to seeing what exciting new biological discoveries arise now that voltage dynamics can be optically monitored with cell-type specificity.

\section{References}

Abbott LF, Regehr WG (2004) Synaptic computation. Nature 431:796-803. CrossRef Medline

Abdelfattah AS, Farhi SL, Zhao Y, Brinks D, Zou P, Ruangkittisakul A, Platisa J, Pieribone VA, Ballanyi K, Cohen AE, Campbell RE (2016) A bright and fast red fluorescent protein voltage indicator that reports neuronal activity in organotypic brain slices. J Neurosci 36:2458-2472. CrossRef Medline

Ahrens KF, Heider B, Lee H, Isacoff EY, Siegel RM (2012) Two-photon scanning microscopy of in vivo sensory responses of cortical neurons genetically encoded with a fluorescent voltage sensor in rat. Front Neural Circuits 6:15. CrossRef Medline

Ainsworth M, Lee S, Cunningham MO, Traub RD, Kopell NJ, Whittington MA (2012) Rates and rhythms: a synergistic view of frequency and temporal coding in neuronal networks. Neuron 75:572-583. CrossRef Medline

Akemann W, Mutoh H, Lundby A, Knöpfel T (2009) Effect of voltage sensitive fluorescent proteins on neuronal excitability. Biophys J 96:39593976. CrossRef Medline

Akemann W, Mutoh H, Perron A, Park YK, Iwamoto Y, Knöpfel T (2012) Imaging neural circuit dynamics with a voltage-sensitive fluorescent protein. J Neurophysiol 108:2323-2337. CrossRef Medline

Akemann W, Sasaki M, Mutoh H, Imamura T, Honkura N, Knöpfel T (2013) Two-photon voltage imaging using a genetically encoded voltage indicator. Sci Rep 3:2231. CrossRef Medline

Antic SD, Empson RM, Knöpfel T (2016) Voltage imaging to understand connections and functions of neuronal circuits. J Neurophysiol 116:135152. CrossRef Medline

Ataka K, Pieribone VA (2002) A genetically targetable fluorescent probe of channel gating with rapid kinetics. Biophys J 82:509-516. CrossRef Medline

Badura A, Sun XR, Giovannucci A, Lynch LA, Wang SS (2014) Fast calcium sensor proteins for monitoring neural activity. Neurophotonics 1:025008. CrossRef Medline

Baird GS, Zacharias DA, Tsien RY (1999) Circular permutation and receptor insertion within green fluorescent proteins. Proc Natl Acad Sci U S A 96:11241-11246. CrossRef Medline

Baker BJ, Lee H, Pieribone VA, Cohen LB, Isacoff EY, Knöpfel T, Kosmidis EK (2007) Three fluorescent protein voltage sensors exhibit low plasma membrane expression in mammalian cells. J Neurosci Methods 161: 32-38. CrossRef Medline

Baker BJ, Mutoh H, Dimitrov D, Akemann W, Perron A, Iwamoto Y, Jin L, Cohen LB, Isacoff EY, Pieribone VA, Hughes T, Knöpfel T (2008) Genetically encoded fluorescent sensors of membrane potential. Brain Cell Biol 36:53-67. CrossRef Medline

Baker BJ, Jin L, Han Z, Cohen LB, Popovic M, Platisa J, Pieribone V (2012) Genetically encoded fluorescent voltage sensors using the voltage-sensing domain of Nematostella and Danio phosphatases exhibit fast kinetics. J Neurosci Methods 208:190-196. CrossRef Medline

Barnett L, Platisa J, Popovic M, Pieribone VA, Hughes T (2012) A fluorescent, genetically-encoded voltage probe capable of resolving action potentials. PLoS One 7:e43454. CrossRef Medline

Bouchard MB, Voleti V, Mendes CS, Lacefield C, Grueber WB, Mann RS, Bruno RM, Hillman EM (2015) Swept confocally-aligned planar excitation (SCAPE) microscopy for high speed volumetric imaging of behaving organisms. Nat Photonics 9:113-119. CrossRef Medline

Boyden ES, Zhang F, Bamberg E, Nagel G, Deisseroth K (2005) Millisecondtimescale, genetically targeted optical control of neural activity. Nat Neurosci 8:1263-1268. CrossRef Medline

Brinks D, Klein AJ, Cohen AE (2015) Two-photon lifetime imaging of voltage indicating proteins as a probe of absolute membrane voltage. Biophys J 109:914-921. CrossRef Medline

Broussard GJ, Liang R, Tian L (2014) Monitoring activity in neural circuits 
with genetically encoded indicators. Front Mol Neurosci 7:97. CrossRef Medline

Cao G, Platisa J, Pieribone VA, Raccuglia D, Kunst M, Nitabach MN (2013) Genetically targeted optical electrophysiology in intact neural circuits. Cell 154:904-913. CrossRef Medline

Carandini M, Shimaoka D, Rossi LF, Sato TK, Benucci A, Knöpfel T (2015) Imaging the awake visual cortex with a genetically encoded voltage indicator. J Neurosci 35:53-63. CrossRef Medline

Carlton PM, Boulanger J, Kervrann C, Sibarita JB, Salamero J, GordonMesser S, Bressan D, Haber JE, Haase S, Shao L, Winoto L, Matsuda A, Kner P, Uzawa S, Gustafsson M, Kam Z, Agard DA, Sedat JW (2010) Fast live simultaneous multiwavelength four-dimensional optical microscopy. Proc Natl Acad Sci U S A 107:16016-16022. CrossRef Medline

Carriles R, Schafer DN, Sheetz KE, Field JJ, Cisek R, Barzda V, Sylvester AW, Squier JA (2009) Invited review article: imaging techniques for harmonic and multiphoton absorption fluorescence microscopy. Rev Sci Instrum 80:081101. CrossRef Medline

Chemla S, Chavane F (2010) Voltage-sensitive dye imaging: technique review and models. J Physiol Paris 104:40-50. CrossRef Medline

Chen TS, Zeng SQ, Luo QM, Zhang ZH, Zhou W (2002) High-order photobleaching of green fluorescent protein inside live cells in two-photon excitation microscopy. Biochem Biophys Res Commun 291:1272-1275. CrossRef Medline

Chen TW, Wardill TJ, Sun Y, Pulver SR, Renninger SL, Baohan A, Schreiter ER, Kerr RA, Orger MB, Jayaraman V, Looger LL, Svoboda K, Kim DS (2013) Ultrasensitive fluorescent proteins for imaging neuronal activity. Nature 499:295-300. CrossRef Medline

Cotton RJ, Froudarakis E, Storer P, Saggau P, Tolias AS (2013) Threedimensional mapping of microcircuit correlation structure. Front Neural Circuits 7:151. CrossRef Medline

Dean KM, Lubbeck JL, Binder JK, Schwall LR, Jimenez R, Palmer AE (2011) Analysis of red-fluorescent proteins provides insight into dark-state conversion and photodegradation. Biophys J 101:961-969. CrossRef Medline

Dimitrov D, He Y, Mutoh H, Baker BJ, Cohen L, Akemann W, Knöpfel T (2007) Engineering and characterization of an enhanced fluorescent protein voltage sensor. PLoS One 2:e440. CrossRef Medline

Dixit R, Cyr R (2003) Cell damage and reactive oxygen species production induced by fluorescence microscopy: effect on mitosis and guidelines for noninvasive fluorescence microscopy. Plant J 36:280-290. CrossRef Medline

Duemani Reddy G, Kelleher K, Fink R, Saggau P (2008) Three-dimensional random access multiphoton microscopy for functional imaging of neuronal activity. Nat Neurosci 11:713-720. CrossRef Medline

Emiliani V, Cohen AE, Deisseroth K, Häusser M (2015) All-optical interrogation of neural circuits. J Neurosci 35:13917-13926. CrossRef Medline

Flytzanis NC, Bedbrook CN, Chiu H, Engqvist MK, Xiao C, Chan KY, Sternberg PW, Arnold FH, Gradinaru V (2014) Archaerhodopsin variants with enhanced voltage-sensitive fluorescence in mammalian and Caenorhabditis elegans neurons. Nat Commun 5:4894. CrossRef Medline

Fujiwara TK, Iwasawa K, Kalay Z, Tsunoyama TA, Watanabe Y, Umemura YM, Murakoshi H, Suzuki KG, Nemoto YL, Morone N, Kusumi A (2016) Confined diffusion of transmembrane proteins and lipids induced by the same actin meshwork lining the plasma membrane. Mol Biol Cell 27:1101-1119. CrossRef Medline

Godley BF, Shamsi FA, Liang FQ, Jarrett SG, Davies S, Boulton M (2005) Blue light induces mitochondrial DNA damage and free radical production in epithelial cells. J Biol Chem 280:21061-21066. CrossRef Medline

Gong Y (2015) The evolving capabilities of rhodopsin-based genetically encoded voltage indicators. Curr Opin Chem Biol 27:84-89. CrossRef Medline

Gong Y, Li JZ, Schnitzer MJ (2013) Enhanced archaerhodopsin fluorescent protein voltage indicators. PLoS One 8:e66959. CrossRef Medline

Gong Y, Wagner MJ, Zhong Li J, Schnitzer MJ (2014) Imaging neural spiking in brain tissue using FRET-opsin protein voltage sensors. Nat Commun 5:3674. CrossRef Medline

Gong Y, Huang C, Li JZ, Grewe BF, Zhang Y, Eismann S, Schnitzer MJ (2015) High-speed recording of neural spikes in awake mice and flies with a fluorescent voltage sensor. Science 350:1361-1366. CrossRef Medline

Gradinaru V, Zhang F, Ramakrishnan C, Mattis J, Prakash R, Diester I, Goshen I, Thompson KR, Deisseroth K (2010) Molecular and cellular approaches for diversifying and extending optogenetics. Cell 141:154-165. CrossRef Medline

Grubb MS, Burrone J (2010) Channelrhodopsin-2 localised to the axon initial segment. PLoS One 5:e13761. CrossRef Medline
Han Z, Jin L, Platisa J, Cohen LB, Baker BJ, Pieribone VA (2013) Fluorescent protein voltage probes derived from ArcLight that respond to membrane voltage changes with fast kinetics. PLoS One 8:e81295. CrossRef Medline

Helmchen F, Denk W (2005) Deep tissue two-photon microscopy. Nat Methods 2:932-940. CrossRef Medline

Helmchen F, Imoto K, Sakmann B (1996) $\mathrm{Ca}^{2+}$ buffering and action potential-evoked $\mathrm{Ca}^{2+}$ signaling in dendrites of pyramidal neurons. Biophys J 70:1069-1081. CrossRef Medline

Helmchen F, Borst JG, Sakmann B (1997) Calcium dynamics associated with a single action potential in a CNS presynaptic terminal. Biophys J 72:1458-1471. CrossRef Medline

Hochbaum DR, Zhao Y, Farhi SL, Klapoetke N, Werley CA, Kapoor V, Zou P, Kralj JM, Maclaurin D, Smedemark-Margulies N, Saulnier JL, Boulting GL, Straub C, Cho YK, Melkonian M, Wong GK, Harrison DJ, Murthy VN, Sabatini BL, Boyden ES, et al. (2014) All-optical electrophysiology in mammalian neurons using engineered microbial rhodopsins. Nat Methods 11:825-833. CrossRef Medline

Hochreiter B, Garcia AP, Schmid JA (2015) Fluorescent proteins as genetically encoded FRET biosensors in life sciences. Sensors 15:26281-26314. CrossRef Medline

Hoppa MB, Gouzer G, Armbruster M, Ryan TA (2014) Control and plasticity of the presynaptic action potential waveform at small CNS nerve terminals. Neuron 84:778-789. CrossRef Medline

Hou JH, Kralj JM, Douglass AD, Engert F, Cohen AE (2014a) Simultaneous mapping of membrane voltage and calcium in zebrafish heart in vivo reveals chamber-specific developmental transitions in iconic currents. Front Physiol 5:344. CrossRef Medline

Hou JH, Venkatachalam V, Cohen AE (2014b) Temporal dynamics of microbial rhodopsin fluorescence reports absolute membrane voltage. Biophys J 106:639-648. CrossRef Medline

Ibraheem A, Campbell RE (2010) Designs and applications of fluorescent protein-based biosensors. Curr Opin Chem Biol 14:30-36. CrossRef Medline

Jin L, Han Z, Platisa J, Wooltorton JR, Cohen LB, Pieribone VA (2012) Single action potentials and subthreshold electrical events imaged in neurons with a fluorescent protein voltage probe. Neuron 75:779-785. CrossRef Medline

Jung A, Garcia JE, Kim E, Yoon BJ, Baker BJ (2015) Linker length and fusion site composition improve the optical signal of genetically encoded fluorescent voltage sensors. Neurophotonics 2:021012. CrossRef Medline

Kang BE, Baker BJ (2016) Pado, a fluorescent protein with proton channel activity can optically monitor membrane potential, intracellular $\mathrm{pH}$, and map gap junctions. Sci Rep 6:23865. CrossRef Medline

Katona G, Szalay G, Maák P, Kaszás A, Veress M, Hillier D, Chiovini B, Vizi ES, Roska B, Rózsa B (2012) Fast two-photon in vivo imaging with three-dimensional random-access scanning in large tissue volumes. Nat Methods 9:201-208. CrossRef Medline

Kibat C, Krishnan S, Ramaswamy M, Baker BJ, Jesuthasan S (2016) Imaging voltage in zebrafish as a route to characterizing a vertebrate functional connectome: promises and pitfalls of genetically encoded indicators. J Neurogenet 30:80-88. CrossRef Medline

Knöpfel T, Gallero-Salas Y, Song C (2015) Genetically encoded voltage indicators for large scale cortical imaging come of age. Curr Opin Chem Biol 27:75-83. CrossRef Medline

Koester HJ, Sakmann B (2000) Calcium dynamics associated with action potentials in single nerve terminals of pyramidal cells in layer $2 / 3$ of the young rat neocortex. J Physiol 529:625-646. CrossRef Medline

Kralj JM, Hochbaum DR, Douglass AD, Cohen AE (2011) Electrical spiking in Escherichia coli probed with a fluorescent voltage-indicating protein. Science 333:345-348. CrossRef Medline

Kralj JM, Douglass AD, Hochbaum DR, Maclaurin D, Cohen AE (2012) Optical recording of action potentials in mammalian neurons using a microbial rhodopsin. Nat Methods 9:90-95. CrossRef Medline

Lai HC, Jan LY (2006) The distribution and targeting of neuronal voltagegated ion channels. Nat Rev Neurosci 7:548-562. CrossRef Medline

Lam AJ, St-Pierre F, Gong Y, Marshall JD, Cranfill PJ, Baird MA, McKeown MR, Wiedenmann J, Davidson MW, Schnitzer MJ, Tsien RY, Lin MZ (2012) Improving FRET dynamic range with bright green and red fluorescent proteins. Nat Methods 9:1005-1012. CrossRef Medline

Lockery SR, Goodman MB (2009) The quest for action potentials in $C$. elegans neurons hits a plateau. Nat Neurosci 12:377-378. CrossRef Medline 
London M, Häusser M (2005) Dendritic computation. Annu Rev Neurosci 28:503-532. CrossRef Medline

Looger LL, Griesbeck O (2012) Genetically encoded neural activity indicators. Curr Opin Neurobiol 22:18-23. CrossRef Medline

Lundby A, Akemann W, Knöpfel T (2010) Biophysical characterization of the fluorescent protein voltage probe VSFP2.3 based on the voltage-sensing domain of Ci-VSP. Eur Biophys J 39:1625-1635. CrossRef Medline

Maclaurin D, Venkatachalam V, Lee H, Cohen AE (2013) Mechanism of voltage-sensitive fluorescence in a microbial rhodopsin. Proc Natl Acad Sci U S A 110:5939-5944. CrossRef Medline

Madisen L, Garner AR, Shimaoka D, Chuong AS, Klapoetke NC, Li L, van der Bourg A, Niino Y, Egolf L, Monetti C, Gu H, Mills M, Cheng A, Tasic B, Nguyen TN, Sunkin SM, Benucci A, Nagy A, Miyawaki A, Helmchen F, et al. (2015) Transgenic mice for intersectional targeting of neural sensors and effectors with high specificity and performance. Neuron 85:942-958. CrossRef Medline

Magidson V, Khodjakov A (2013) Circumventing photodamage in live-cell microscopy. Methods Cell Biol 114:545-560. CrossRef Medline

McIsaac RS, Engqvist MK, Wannier T, Rosenthal AZ, Herwig L, Flytzanis NC, Imasheva ES, Lanyi JK, Balashov SP, Gradinaru V, Arnold FH (2014) Directed evolution of a far-red fluorescent rhodopsin. Proc Natl Acad Sci U S A 111:13034-13039. CrossRef Medline

Mishina Y, Mutoh H, Knöpfel T (2012) Transfer of Kv3.1 voltage sensor features to the isolated Ci-VSP voltage-sensing domain. Biophys J 103: 669-676. CrossRef Medline

Mishina Y, Mutoh H, Song C, Knöpfel T (2014) Exploration of genetically encoded voltage indicators based on a chimeric voltage sensing domain. Front Mol Neurosci 7:78. CrossRef Medline

Mutoh H, Akemann W, Knöpfel T (2012) Genetically engineered fluorescent voltage reporters. ACS Chem Neurosci 3:585-592. CrossRef Medline

Nakai J, Ohkura M, Imoto K (2001) A high signal-to-noise Ca(2+) probe composed of a single green fluorescent protein. Nat Biotechnol 19: 137-141. CrossRef Medline

Nickell WT, Pun RY, Bargmann CI, Kleene SJ (2002) Single ionic channels of two Caenorhabditis elegans chemosensory neurons in native membrane. J Membr Biol 189:55-66. CrossRef Medline

Packer AM, Russell LE, Dalgleish HW, Häusser M (2015) Simultaneous alloptical manipulation and recording of neural circuit activity with cellular resolution in vivo. Nat Methods 12:140-146. CrossRef Medline

Park J, Werley CA, Venkatachalam V, Kralj JM, Dib-Hajj SD, Waxman SG, Cohen AE (2013) Screening fluorescent voltage indicators with spontaneously spiking HEK cells. PLoS One 8:e85221. CrossRef Medline

Patterson GH, Piston DW (2000) Photobleaching in two-photon excitation microscopy. Biophys J 78:2159-2162. CrossRef Medline

Perron A, Mutoh H, Akemann W, Gautam SG, Dimitrov D, Iwamoto Y, Knöpfel T (2009) Second and third generation voltage-sensitive fluorescent proteins for monitoring membrane potential. Front Mol Neurosci 2:5. CrossRef Medline

Peterka DS, Takahashi H, Yuste R (2011) Imaging voltage in neurons. Neuron 69:9-21. CrossRef Medline

Pflaum M, Kielbassa C, Garmyn M, Epe B (1998) Oxidative DNA damage induced by visible light in mammalian cells: extent, inhibition by antioxidants and genotoxic effects. Mutat Res 408:137-146. CrossRef Medline

Piao HH, Rajakumar D, Kang BE, Kim EH, Baker BJ (2015) Combinatorial mutagenesis of the voltage-sensing domain enables the optical resolution of action potentials firing at $60 \mathrm{~Hz}$ by a genetically encoded fluorescent sensor of membrane potential. J Neurosci 35:372-385. CrossRef Medline

Scott G, Fagerholm ED, Mutoh H, Leech R, Sharp DJ, Shew WL, Knöpfel T (2014) Voltage imaging of waking mouse cortex reveals emergence of critical neuronal dynamics. J Neurosci 34:16611-16620. CrossRef Medline

Shaner NC, Steinbach PA, Tsien RY (2005) A guide to choosing fluorescent proteins. Nat Methods 2:905-909. CrossRef Medline

Shaner NC, Lambert GG, Chammas A, Ni Y, Cranfill PJ, Baird MA, Sell BR, Allen JR, Day RN, Israelsson M, Davidson MW, Wang J (2013) A bright monomeric green fluorescent protein derived from Branchiostoma lanceolatum. Nat Methods 10:407-409. CrossRef Medline

Siegel MS, Isacoff EY (1997) A genetically encoded optical probe of membrane voltage. Neuron 19:735-741. CrossRef Medline

Sitaraman D, Aso Y, Jin X, Chen N, Felix M, Rubin GM, Nitabach MN (2015) Propagation of homeostatic sleep signals by segregated synaptic microcir- cuits of the Drosophila mushroom body. Curr Biol 25:2915-2927. CrossRef Medline

Storace DA, Braubach OR, Jin L, Cohen LB, Sung U (2015) Monitoring brain activity with protein voltage and calcium sensors. Sci Rep 5:10212. CrossRef Medline

Storace D, Sepehri Rad M, Kang B, Cohen LB, Hughes T, Baker BJ (2016) Toward better genetically encoded sensors of membrane potential. Trends Neurosci 39:277-289. CrossRef Medline

St-Pierre F, Marshall JD, Yang Y, Gong Y, Schnitzer MJ, Lin MZ (2014) High-fidelity optical reporting of neuronal electrical activity with an ultrafast fluorescent voltage sensor. Nat Neurosci 17:884-889. CrossRef Medline

St-Pierre F, Chavarha M, Lin MZ (2015) Designs and sensing mechanisms of genetically encoded fluorescent voltage indicators. Curr Opin Chem Biol 27:31-38. CrossRef Medline

Stuart GJ, Spruston N (2015) Dendritic integration: 60 years of progress. Nat Neurosci 18:1713-1721. CrossRef Medline

Sung U, Sepehri-Rad M, Piao HH, Jin L, Hughes T, Cohen LB, Baker BJ (2015) Developing fast fluorescent protein voltage sensors by optimizing FRET interactions. PLoS One 10:e0141585. CrossRef Medline

Svoboda K, Yasuda R (2006) Principles of two-photon excitation microscopy and its applications to neuroscience. Neuron 50:823-839. CrossRef Medline

Tan TT, Khaw C, Ng MM (2010) Challenges and recent advances in live cell bioimaging. In: Microscopy: science, technology, application and education, pp 1495-1505. Barcelona: Formatex Research Center.

Tantama M, Hung YP, Yellen G (2012) Optogenetic reporters: fluorescent protein-based genetically-encoded indicators of signaling and metabolism in the brain. Prog Brain Res 196:235-263. CrossRef Medline

Treger JS, Priest MF, Bezanilla F (2015) Single-molecule fluorimetry and gating currents inspire an improved optical voltage indicator. Elife 4:e10482. CrossRef Medline

Truong TV, Supatto W, Koos DS, Choi JM, Fraser SE (2011) Deep and fast live imaging with two-photon scanned light-sheet microscopy. Nat Methods 8:757-760. CrossRef Medline

Tsutsui H, Karasawa S, Okamura Y, Miyawaki A (2008) Improving membrane voltage measurements using FRET with new fluorescent proteins. Nat Methods 5:683-685. CrossRef Medline

Tsutsui H, Jinno Y, Tomita A, Niino Y, Yamada Y, Mikoshiba K, Miyawaki A, Okamura Y (2013) Improved detection of electrical activity with a voltage probe based on a voltage-sensing phosphatase. J Physiol 591:44274437. CrossRef Medline

Tsytsarev V, Liao LD, Kong KV, Liu YH, Erzurumlu RS, Olivo M, Thakor NV (2014) Recent progress in voltage-sensitive dye imaging for neuroscience. J Nanosci Nanotechnol 14:4733-4744. CrossRef Medline

Wilt BA, Burns LD, Wei Ho ET, Ghosh KK, Mukamel EA, Schnitzer MJ (2009) Advances in light microscopy for neuroscience. Annu Rev Neurosci 32:435-506. CrossRef Medline

Wilt BA, Fitzgerald JE, Schnitzer MJ (2013) Photon shot noise limits on optical detection of neuronal spikes and estimation of spike timing. Biophys J 104:51-62. CrossRef Medline

Wolf S, Supatto W, Debrégeas G, Mahou P, Kruglik SG, Sintes JM, Beaurepaire E, Candelier R (2015) Whole-brain functional imaging with two-photon lightsheet microscopy. Nat Methods 12:379-380. CrossRef Medline

Yang HH, St-Pierre F, Sun X, Ding X, Lin MZ, Clandinin TR (2016) Subcellular imaging of voltage and calcium signals reveals neural processing in vivo. Cell 166:245-257. CrossRef Medline

Zhang H, Reichert E, Cohen AE (2016) Optical electrophysiology for probing function and pharmacology of voltage-gated ion channels. Elife 5:e15202. CrossRef Medline

Zhao Y, Araki S, Wu J, Teramoto T, Chang YF, Nakano M, Abdelfattah AS, Fujiwara M, Ishihara T, Nagai T, Campbell RE (2011) An expanded palette of genetically encoded $\mathrm{Ca}^{2+}$ indicators. Science 333:1888-1891. CrossRef Medline

Zheng H, Liu W, Anderson LY, Jiang QX (2011) Lipid-dependent gating of a voltage-gated potassium channel. Nat Commun 2:250. CrossRef Medline

Zou P, Zhao Y, Douglass AD, Hochbaum DR, Brinks D, Werley CA, Harrison DJ, Campbell RE, Cohen AE (2014) Bright and fast multicoloured voltage reporters via electrochromic FRET. Nat Commun 5:4625. CrossRef Medline 